\title{
ANALISIS SALURAN DISTRIBUSI DAN EFISIENSI PEMASARAN PUPUK BERSUBSIDI DI KECAMATAN SELAKAU KABUPATEN SAMBAS
}

\author{
Watiha $^{1)}$, A.Hamid.A.Yusra ${ }^{2)}$, Dewi Kurniati ${ }^{2)}$ \\ 1) Mahasiswa Fakultas Pertanian Universitas Tanjungpura \\ 2) Dosen Fakultas Pertanian Universitas tanjungpura
}

\begin{abstract}
Have been done conducted by research with the title analyse the channel of distribution and marketing efficiency fertilize to subsidize in subdistrict selakau, regency sambas to know the distribution process fertilize to subsidize from Petrochemical PT Pusri and PT of Gresik to paddy farmer and to know the level of marketing expense, swampy forest price ( price spread) and share margin which is in accepted by each channeling institute fertilize to subsidize. Data collected with the observation and interview to farmer. this Research population is farmer, producer, distributor, formal retailer and also retailer. election Sampel (responden) done conducted by determining sampel farmer ( simple random sampling), sampel merchant determined by snowball is sampling.Result of research show, that pattern of distribution or channeling fertilize to subsidize in subdistrict of selakau of regency sambas of disagree with decision of SK Menperindak No. 17/M-DAG/PER/6/2011 that is first the than producer to distributor, laterthen to formal retailer then to retailer and last to consumer. Channeling fertilize to subsidize done conducted in subdistrict selakau indicate that the biggest margin value released by distributor institute whereabout fertilize the urea Rp. 400.16 / Singk of Za Rp. 1.136.16 / Singk of SP36 Rp. 522.16 / Singk of NPK Rp. 298.16 / Organic singk of Rp. 400.2 / Singk institute this represent the inefficient marketing channel of own the high in comparing formal institute retailer and retailer. While smallest marketing expense in releasing by institute of retailer whereabout to fertilize the urea Rp. 345 / singk of Za Rp. 345

/ singk SP 36 Rp. 432 / singk of NPK Rp. 445 / organic singk of Rp.545 / singk, hence earn in concluding that channel of marketing of retailer is efficient marketing channel if in comparing with channel of marketing of formal retailer and distributor of karna own the low and obtain get the highest value share margin.
\end{abstract}

Keywords: Margin, Efficiency, fertilize to subsidize. 


\section{PENDAHULUAN}

Permasalahan pertanian di Indonesia masih banyak mengalami kendala, salah satunya adalah menyangkut masalah rendahnya produktivitas pertanian. Hal ini terjadi karena sistem pertanian yang dikerjakan oleh petani biasanya masih bersifat tradisional yaitu lebih banyak menggunakan tenaga manusia dan hanya mengharapkan kesuburan tanah secara alamiah. Oleh karena itu, dibutuhkan suatu upaya peningkatan produktivitas lahan dan pemberdayaan petani, diantaranya adalah melalui upaya pemupukan dengan dosis standar atau Standar Operation Prosedur (SOP). Dipihak lain mahalnya harga pupuk membuat petani terkadang memilih jalan untuk tidak mempergunakan pupuk, padahal pupuk merupakan salah satu faktor produksi yang sangat mempengaruhi jumlah produksi. Hasil produksi tidak akan dapat mencapai hasil yang maksimal jika dalam kegiatan usaha tani saja tidak dilaksanakan secara tepat dan benar. Untuk itu, sebagai tindak lanjut untuk penanggulangan dalam menyikapi permasalahan tersebut maka pemerintah menempuh kebijakan bantuan pupuk bersubsidi.

Pupuk bersubsidi merupakan pupuk yang pengadaan dan penyalurannya mendapat subsidi dari pemerintah untuk kebutuhan petani yang dilaksanakan atas dasar program pemerintah (SK Menperindag 306/MPP/Kep/4/2003). Pupuk yang mendapat subsidi dari pemerintah tidak diberikan secara gratis tapi dapat dibeli dengan harga yang terjangkau. Pupuk yang disubsidikan oleh pemerintah adalah jenis pupuk Urea, SP-36, ZA, NPK Phonska dan pupuk organik.

Tabel 1. Het pupuk bersubsidi pada tahun 2012 ( $\mathrm{Rp} / \mathrm{Kg})$

\begin{tabular}{cc}
\hline Jenis Pupuk & $(\mathrm{Rp} / \mathrm{Kg})$ \\
\hline Urea & 1.800 \\
SP - 36 & 2.000 \\
ZA & 1.400 \\
Phonska & 2.300 \\
Organik & 500 \\
\hline
\end{tabular}

Sumber:Dinas Pertanian Kabupaten Sambas, 2012

Kalimantan barat sebagai salah satu provinsi yang cukup besar pertaniannya sehingga perlu di penuhi kebutuhan pupuknya. Kebutuhan pupuk bersubsidi untuk sektor pertanian untuk tahun anggran 2011 yakni pupuk urea sebesar 42,000.00 / ton, SP-36 sebanyak 8,824.00/ton, ZA sebanyak 4,500.00/ton, NPK sebanyak 41,000.00/ton, organik 6,500.00/ton. Kabupaten Sambas merupakan salah satu daerah yang memiliki kebutuhan pupuk yang besar yakni pupuk urea sebanyak 9,530.00/ton atau sebesar $22,70 \%$, SP-36 sebanyak 1,703.65/ton atau sebesar 19,30\%, ZA sebanyak 1,039.00/ton atau sebesar $23,10 \%$, NPK sebanyak 6,092.00/ton atau sebesar $15 \%$, dan Organik sebanyak 917.10 /ton atau sebesar $14,10 \%$ dari rata-rata kebutuhan pupuk bersubsidi di Kalimantan Barat.

Kecamatan selakau merupakan salah satu kecamatan yang terdapat di kabupaten sambas. Mayoritas penduduk di Kecamatan Selakau bermata pencaharian sebagai petani, terutama petani padi yang kebutuhan pupuknya cukup besar yakni pupuk urea sebanyak 851/ton atau 9\%, ZA sebesar 77.20/ton atau di persenkan sekitar 7,42\%,SP-36 sebesar 153.82/ton atau sekitar $9 \%$, NPk sebesar 485.06 /ton atau $8 \%$ dan pupuk organik sebesar $87.95 /$ ton atau di persenkan sekitar 9,59\% .Hal ini merupakan yang mendorong peneliti untuk melakukan penelitian di kecamatan selakau selain kebutuhan pupuknya yang cukup besar alasan lainnya adalah mudahnya peneliti mendapatkan informasi dalam melakukan penelitian selain itu juga dekatnya jarak tempuh untuk melakukan penelitian adanya sarana dan prasarana transportasi yang mendukung. 
Demi tercapainya kelancaran pupuk bersubsidi sebagai tindak lanjut SK Menperindag No.17/M- DAG/PER/6/2011 pola pendistribusian pupuk bersubsidi yang berawal dari PT Pupuk Sriwidjaja (Pusri) selaku produsen pupuk bersubsidi menentukan wilayah tanggung jawab pengadaan dan penyaluran pupuk bersubsidi kepada distributor yang ditunjuknya. Distributor memiliki tanggung jawab menyalurkan pupuk bersubsidi dari produsen kepengecer resmi kemudian pihak pengecer melakukan pendistribusian pupuk bersubsidi langsung kepada petani atau kelompok tani yang di bantu oleh pengecer binaan.

Pengaturan saluran distribusi pupuk bersubsidi yang di atur sedemikian rupa oleh pemerintahadalah dengan sasaran tersedianya pupuk subsidi di tingkat petani secara enam tepat yakni tepat jumlah, jenis, waktu, tempat dengan mutu terjamin dan harga sesuai dengan HET yang di tetapkan pemerintah. Namun pada kenyataan di lapangan tidak berjalan dengan apa yang telah di tentukan oleh pemerintah, kenyataannya di sini di temukan terjadinya perbedaan harga yang sangat jauh antar harga yang telah di tetapkan oleh pemerintah atau HET ( Harga Eceran Tertinggi ) dengan harga di tingkat pengecer.

Tabel 2. Data Perbedaan Harga Antara Harga Pemerintah Dengan Harga di Tingkat Pengecer Tahun 2012

\begin{tabular}{cccc}
\hline NO & JENIS PUPUK & $\begin{array}{r}\text { HARGA PEMERINTAH } \\
\text { Rp/ Kg }\end{array}$ & $\begin{array}{c}\text { HARGA DI TINGKAT } \\
\text { PENGECER Rp/ Kg }\end{array}$ \\
\hline 1 & UREA & 1.800 & 3.000 \\
2 & SP-36 & 2.000 & 3.000 \\
3 & ZA & 1.400 & 3.500 \\
4 & NPK & 2.300 & 3.000 \\
5 & Organik & 500 & 1.500 \\
\hline
\end{tabular}

Sumber: Analisis Data Primer,2012

Dengan perbedaan harga dari tingkat produsen dan konsumen maka akan terdapat perbedaan margin yang diterima oleh lembaga- lembaga terkait dalam pendistribusian pupuk bersubsidi. Dengan melihat begitu tingginya perbedaan harga antara yang di terima pengecer dan bagian yang di terima petani perlu mendapat perhatian yang serius.

\section{Permasalahan}

permasalahan dalam penelitian ini yaitu:

1. Bagaimana proses distribusi pupuk bersubsidi dari PT Pusri dan PT Petrokimia Gresik sampai ke petani padi?

2. Berapa besar margin pemasaran, price spread, share margin, setiap lembaga pemasaran yang terlibat dalam saluran pemasaran

\section{Tujuan Penelitian}

tujuan didalam penelitian ini adalah sebagai berikut:

1. Untuk mengetahui proses distribusi pupuk bersubsidi dari PT Pusri dan PT Petrokimia Gresik sampai ke petani padi.

2. Untuk mengetahui besarnya biaya pemasaran, sebaran harga ( price spread) dan share margin yang di terima oleh masing-masing lembaga penyaluran pupuk bersubsidi. 


\section{Kegunaan Penelitian}

1. Penelitian inidiharapkan dapat dijadikan sebagai bahan pertimbangan bagi pemerintah untuk menyusun dan mengambil kebijaksanaan yang lebih tegas lagi dalam hal saluran distribusi pupuk bersubsidi sehingga tepat sasaran.

2. Memberikan sumbangan pemikiran dan gambaran bagi petani-petani tentang harga pupuk bersubsidi khususnya dalam perubahan harga yang terjadi di setiap lembaga pemasaran.

3. Sebagai bahan informasi dan referensi bagi peneliti lainnya yang berhubungan dengan penelitian ini.

\section{METODE PENELITIAN}

\section{Metode Penelitian dan Penentuan}

\section{Lokasi}

Metode yang digunakan dalam penelitian ini adalah survey. Lokasi penelitian ditentukan secara sengaja (purposive) di Kecamatan Selakau denganpertimbangan bahwa daerah tersebut merupakan salah satu daerah yang kebutuhan pupuknya cukup besar.

\section{Populasi dan Teknik Penetapan Sampel}

Populasi dalam penelitian ini berjumlah 3.110 orang petani yang terdiri dari 121 kelompok tani. Dalam penelitian ini sampel produsen dan lembaga pemasaran di tentukan secara snowball sampling. Sedangkan cara pengambilan sampel petani dilakukan dengan cara acak dari populasi sasaran dengan menggunakan metode simple random sampling.

\section{Sumber dan Teknik Pengumpulan \\ Data}

Sumber data yang di peroleh yaitu:

1. Data primer adalah sumber data yang dengan cara melakukan wawancara atau melakukan pendekatan secara personal atau individu dengan narasumber yang terpercaya.

2. Data sekunder adalah sumber data yang tidak langsung memberikan data kepada pengumpul data misalnya kepada orang lain atau lewat dokumen.

Teknik pengumpulan data dapat di lakukan dengan berbagai cara yaitu:

1. Data primer di dapat dengan wawancara langsung dengan responden antaralain produsen pupuk, distributor, pedagang pengecer resmi dan nonresmi, dan petani yang di lengkapi dengan daftar pertanyaan (kuisioner).

2. Data sekunder di peroleh dari instansi atau lembaga terkait seperti BPS, Dinas Peranian, PT Pusri, PD Harapan Pajar serta literatur yang mendukung dalam melengkapi data yang di perlukan dalam penelitian ini. 


\section{Variabel Penelitian}

Variabel yang akan dianalisa dalam penelitian ini adalah sebagai berikut:

a. Distribusi pupuk bersubsidi adalah proses penyaluran pupuk subsidi dari produsen sampai ke tangan konsumen (Petani).

b. Margin pemasaran pupuk bersubsidi adalah perbedaan harga yang dibayarkan oleh konsumen akhir dengan harga yang diterima oleh pengecer pupuk bersubsidi. Satuan yang digunakan yaitu rupiah per kilogram $(\mathrm{Rp} / \mathrm{Kg})$.

c. Harga pupuk bersubsidi adalah harga yang diterima ditingkat pengecer pupuk bersubsidi, lembaga perantara terkait didalamnya dan konsumen. Satuan yang digunakan dalam rupiah per kilogram $(\mathrm{Rp} / \mathrm{Kg})$, yaitu:

1). Harga ditingkat PT Pusri dan PT Petrokimia Gresik adalah harga yang diterima PT Pusri dan PT Petrikimia Gresik dari hasil penjualan kepada distributor dan pedagang pengecer.

2). Harga ditingkat distributor adalah harga yang diterima pedagang besar dari hasil penjualan kepada pedagang pengecer.

3). Harga ditingkat pedagang pengecer adalah harga yang diterima pedagang pengecer dari hasil penjualan kepada konsumen atau harga yang dibayarkan oleh konsumen.

4) Harga ditingkat konsumen adalah harga yang diterima konsumen dari penjualan ditingkat pengecer.

d. Biaya Penyaluran Pupuk Bersubsidi terdiri dari biaya transportasi dan upah buruh yaitu biaya yang dikeluarkan secara langsung dalam pemberian jasa kegiatan penyaluran pupuk bersubsidi. Satuan yang digunakan dalam biaya pemasaran adalah rupiah per kilogram $(\mathrm{RP} / \mathrm{Kg})$.

e. Price spread (sebaran harga) adalah pengelompokan harga beli, harga jual, biaya pemasaran dan keuntungan yang di peroleh setiap lembaga pemasaran.

f. Share margin adalah harga yang di terima oleh setiap lembaga pemasaran terhadap harga beli konsumen dalam bentuk persen (\%).

\section{Analisis Data}

1. Margin Pemasaran

Untuk menghitung Margin pupuk bersubsidi dapat diketahui dengan rumus sebagai berikut:

$M j i=$ Pri - Pfi atau $M j i=b i+K i$

dimana :

Mji = Margin Penyaluran pupuk bersubsidi

Pri $=$ Harga ditingkat distributor

$\mathrm{Pfi}=$ Harga ditingkat pengecer

$\mathrm{Bi}$ = Biaya penyaluran pupuk bersubsidi

$\mathrm{Ki}=$ Keuntungan penyaluran subsidi pupuk

$\mathrm{N}=$ Jumlah lembaga penyaluran pupuk bersubsidi

\{(Hamim,1989:16) dalam Andi (2005:28)\} 
Aplikasi dalam penelitian ini menjadi :

$\mathrm{Mjp}=\mathrm{bp}+\mathrm{kp}$

$\mathrm{Mjc}=\mathrm{bc}+\mathrm{kc}$

Keterangan :

Mjp = Margin pedagang besar

$\mathrm{Bp} \quad=$ Biaya penyaluran pupuk bersubsidi pedagang besar

$\mathrm{kp} \quad=$ Keuntungan pedagang besar

Mjc = Margin pedagang pengecer

$\mathrm{Bc}=$ Biaya pemasaran pedagang pengecer

$\mathrm{kc} \quad=$ Keuntungan pedagang pengecer

2. menghitung share margin menggunakan rumus:

$$
\mathrm{SM}=\frac{\mathrm{PP}}{\mathrm{PK}} \times 100 \%
$$

Dimana :

sm : persentase margin yang di hitung dalam persen

Pp : : harga yang di terima produsen dan pedagang

Pk : harga yang di bayar oleh konsumen akhir Gultom (1996) dalam Melda (2007:37).

3. Price spread adalah pengelompokan harga beli, harga jual, biaya pemasaran dan keuntungan yang di peroleh setiap lembaga pemasaran.

4. Efisiensi pemasaran adalah nisbah antara biaya pemasaran dengan nilai produk yang di jual, dinyatakan dengan persen menurut soekartawi (2002:3).

$$
E p=\frac{B P}{H E} \quad x 100 \%
$$

Dimana :

$\mathrm{Ep}=$ Efisiensi Pemasaran

$\mathrm{Bp}=$ Biaya Pemasaran

$\mathrm{HE}=$ Harga Eceran

Kriteria : - Eps < $5 \%$ Efisien

- Eps $>5 \%$ tidak Efisien

5. Analisis Deskriptif adalah analisa yang menggambarkan (melukiskan) keadaan obyek penelitian pada saat sekarang berdasarkan fakta-fakta yang tampak atau sebagaimana adanya. 


\section{HASIL DAN PEMBAHASAN}

\section{Saluran Distribusi Pupuk Urea, ZA. SP-36, NPK dan Organik Bersubsidi.}

Sistem distribusi pupuk saat ini di atur oleh Menteri Perdagangan. Pengaturan sistem distribusi pupuk ini dengan harapan agar petani dapat memperoleh pupuk dengan 6 azas tepat, yaitu : tempat, jenis, waktu, jumlah, mutu, dan harga. Saluran pemasaran pupuk bersubsidi Urea, ZA, SP-36, NPK, Oraganik pada umumnya melibatkan produsen, distributor dan pengecer. Saluran ini sudah di atur dalam sebuah peraturan pemerintah yang terdapat pada SK Menperindak No. 17/M- DAG/PER/6/2011. Dalam SK tersebut di jelaskan bahwa untuk kelancaran pendistribusian pupuk bersubsidi menjadi tanggung jawab produsen, distributor dan pengecer resmi. Tetapi pada kenyataan di lapangan saluran pemasaran pupuk bersubsidi yang terdapat di daerah penelitian tidak mengikuti ketetapan SK Menperindak No. 17/M- DAG/PER/6/2011. Adapun saluran pemasaran pupuk bersubsidi yang ada di daerah penelitian adalah sebagai berikut:

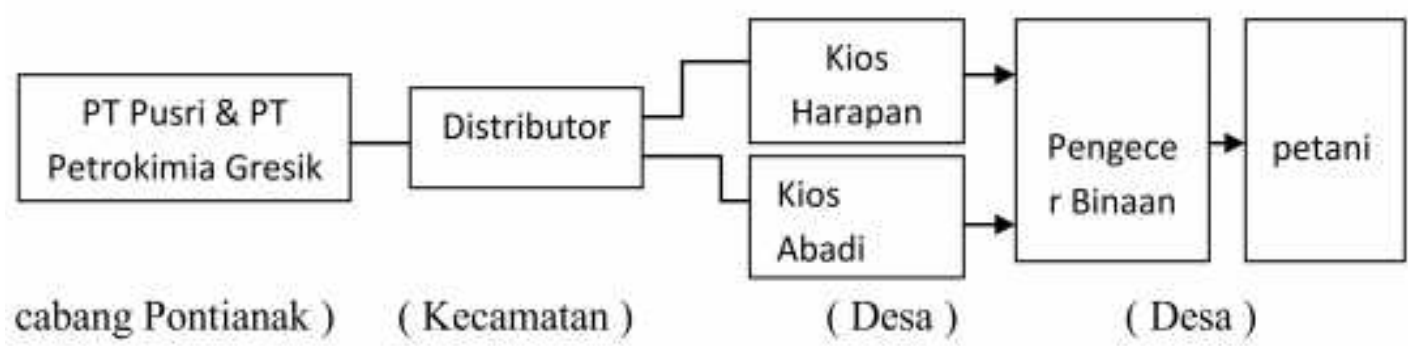

Gambar 1. Saluran Distribusi Pupuk Bersubsidi di Kecamatan Selakau Kab. Sambas

Tujuan awal di bentuknya pengecer binaan dengan harapan agar pupuk tersebar merata kepada petani agar para petani dengan mudahnya mendapatkan pupuk bersubsidi tetapi pada satu sisi dengan di bentuknya pengecer binaan justru membuat harga pupuk bersubsidi sangat jauh dari yang di tetapkan berdasarkan Harga Eceran Tertnggi Pemerintah. Di sini para pengecer binaan dengan mudahnya memainkan harga pupuk bersubsidi kepada petani maka petani itu sendiri yang di rugikan, hal ini terjadi karna kurangnya atau lemahnya pengawasan yang di lakukan oleh KP3.

Peran dan tugas yang di limpahkan kepada pengecer resmi tidak seutuhnya di jalankan atau di laksanakan sebagaimana mestinya di mana tugas pokok pengecer resmi adalah melakukan penjualan pupuk bersubsidi secara langsung kepada petani atau kelompok tani di wilayah kerjanya, tapi di lapangan tidak menunjukan hal tersebut sebelum pupuk bersubsidi di distribusikan kepada petani atau kelompok tani tapi melalui pengecer binaan yang sudah tersebar di wilayah kerjanya.

Pada dasarnya petani yang ada di daerah penelitian tidak bisa membeli langsung pupuk bersubsidi ke pengecer resmi hal ini terjadi karna di sebabkan sedikitnya jumlah pengecer resmi yang ada di daerah penelitian sehingga menimbulkan terbentuknya pengecer binaan hal ini di lakukan agar para petani mudah dalam mendapatkan pupuk bersubsidi karna pupuk tersebut tersebar luas di wilayah tanggungjawab kerja pengecer resmi. Jadi para petani di tuntut untuk mengikuti saluran pemasaran yang ada walaupun hal itu sendiri dapat merugikan para petani itu sendiri.

2. Analisis Margin Pemasaran, Price Spread, Share Margin dan Efisiensi Pemasaran Pada Setiap Lembaga Pemasaran yang Terlibat. 
Tabel 3. Perhitungan Nilai Margin Pemasaran Pupuk Bersubsidi untuk Setiap Lembaga Pemasaran

\begin{tabular}{lccccc}
\hline \multirow{2}{*}{ Lembaga Pemasaran } & \multicolumn{5}{c}{ Margin Pemasaran Pupuk Bersubsidi ( Kg/Rp) } \\
\cline { 2 - 6 } & Urea & ZA & SP 36 & NPK & Organik \\
\hline 1. Distributor & & & & & \\
PD Harapan Pajar & 400.16 & 1.136 .16 & 522.16 & 298.16 & 400.2 \\
2. Pengecer Resmi & & & & & \\
a. Kios Abadi & 685 & 785 & 385 & 285 & 335 \\
b. Kios Harapan pajar & 671.58 & 755.79 & 355.79 & 271.58 & 295.23 \\
3. Kios Binaan & & & & & \\
a. Hadiri & 345 & 539 & 493 & 445 & 523 \\
b. Hamdan & 342 & 525 & 425 & 442 & 564 \\
c. Rusdi & 345 & 532 & 432 & 445 & 545 \\
d. Lomeu & 345 & 526 & 432 & 451 & 545 \\
e. Nardi & 345 & 532 & 432 & 445 & 545 \\
f. Suwardi & 345 & 532 & 432 & 445 & 545 \\
g. M. A. Halim & 351 & 626 & 432 & 445 & 545 \\
\hline
\end{tabular}

Sumber : Analisis Data Primer,2012

Berdasarkan tabel 3 di atas dapat diketahui bahwa margin pemasaran terbesar diperoleh oleh lembaga distributor di mana pupuk urea Rp. $400.16 / \mathrm{Kg} \mathrm{Za} \mathrm{Rp.} 1.136 .16 / \mathrm{Kg} \mathrm{SP36}$ Rp. 522.16/Kg NPK Rp. 298.16/Kg organik Rp. 400.2/Kg lembaga ini merupakan saluran pemasaran yang tidak efisien karna memiliki margin tataniaga yang tinggi di bandingkan lembaga tataniaga pengecer resmi dan pengecer binaan. Sedangkan margin pemasaran terkecil di keluarkan oleh lembaga pengecer binaan di mana untuk pupuk urea Rp. 345/kg Za Rp. 345/kg SP 36 Rp. 432/kg NPK Rp. 445/kg organik Rp.545/kg.

Tabel 4. Perhitungan Nilai Harga Jual, Harga Beli dan Keuntungan pada Setiap Lembaga Pemasaran

\begin{tabular}{llccc}
\hline $\begin{array}{c}\text { Lembaga } \\
\text { Pemasaran }\end{array}$ & \multicolumn{1}{c}{ Jenis } \\
Pupuk & Harga Beli & Harga Jual & Keuntungan \\
\hline Distributor & 1. Urea & 1.725 & 2.100 & 375 \\
& 2. ZA & 1.240 & 2.300 & 1.060 \\
& 3. SP 36 & 1.850 & 2.300 & 450 \\
& 4. NPK & 2.180 & 2.400 & 220 \\
5engecer Resmi & 5. Organik & 440 & 750 & 310 \\
& 1. Urea & 2.100 & 2.700 & 600 \\
& 2. ZA & 2.300 & 3.000 & 700 \\
& 3. SP 36 & 2.300 & 2.600 & 300 \\
& 4. NPK & 2.400 & 2.600 & 400 \\
Pengecer Binaan & 5. Organik & 750 & 1.000 & 250 \\
& 1. Urea & 2.700 & 3.000 & 300 \\
& 2. ZA & 3.000 & 3.500 & 500 \\
& 3. SP 36 & 2.600 & 3.000 & 400 \\
& 4. NPK & 2.600 & 3.000 & 400 \\
& 5. Organik & 1.000 & 1.500 & 500 \\
\hline
\end{tabular}

Sumber : Analisis Data Primer,2012 
Tabel di atas menunjukan bahwa keuntungan yang di peroleh setiap lembaga pemasaran khususnya untuk lembaga pemasaran resmi dan pengecer binaan menunjukan nilai yang tidak begitu jauh beda walaupun nilai margin yang di keluarkan oleh oleh pengecer resmi lebih besar dari pengecer binaan karna harga beli yang di terima oleh pengecer binaan dari pengecer resmi sangat mahal atau tinggi, tingginya harga yang di peroleh pengecer binaan menyebabkan harga jual di tingkat petani tinggi atau melebihi Harga Eceran Pemerintah.

Tabel 5. Perhitungan Nilai Share Margin Pemasaran Pupuk Bersubsidi untuk Setiap Lembaga Pemasaran

\begin{tabular}{llllll}
\hline \multirow{2}{*}{ Lembaga Pemasaran } & \multicolumn{5}{c}{ Share Margin Pemasaran Pupuk Bersubsidi (\%) } \\
\cline { 2 - 6 } & Urea & ZA & SP 36 & NPK & Organik \\
\hline 1. Distributor & 57.5 & 35.42 & 61.67 & 72.67 & 29.34 \\
$\begin{array}{l}\text { PD Harapan Pajar } \\
\text { 2. Pengecer Resmi }\end{array}$ & & & & & \\
a. Kios Abadi & 70 & 65.71 & 76.67 & 80 & 50 \\
b. Kios Harapan pajar & 70 & 65.71 & 76.67 & 80 & 50 \\
3. Kios Binaan & & & & & \\
a. Hadiri & 90 & 85.71 & 86.67 & 86.67 & 66.67 \\
b. Hamdan & 90 & 85.71 & 86.67 & 86.67 & 66.67 \\
c. Rusdi & 90 & 85.71 & 86.67 & 86.67 & 66.67 \\
d. Lomeu & 90 & 85.71 & 86.67 & 86.67 & 66.67 \\
e. Nardi & 90 & 85.71 & 86.67 & 86.67 & 66.67 \\
f. Suwardi & 90 & 85.71 & 86.67 & 86.67 & 66.67 \\
g. M. A. Halim & 90 & 85.71 & 86.67 & 86.67 & 66.67 \\
\hline
\end{tabular}

Sumber : Analisis Data Primer,2012

Dengan melihat Tabel di atas dapat diketahui bahwa nilai share margin terbesar terdapat pada pengecer binaan, kemudian pengecer kios resmi dan yang paling rendah adalah distributor. Hal ini terjadi karena saluran pemasaran yang di lakukan distributor panjang dan serta wilayah kerjanya luas di bandingkan lembaga pengecer resmi dan kios binaan sehingga biaya transportasi yang dikeluarkan menjadi lebih besar. Hal ini membuktikan bahwa semakin kecil marjin pemasaran maka share margin yang diterima akan semakin besar.

Tabel 6. Perhitungan Efisiensi Pemasaran Pupuk Bersubsidi untuk Setiap Lembaga Pemasaran

\begin{tabular}{lccccc}
\hline \multirow{2}{*}{ Lembaga Pemasaran } & \multicolumn{5}{c}{ Share Margin Pemasaran Pupuk Bersubsidi (\%) } \\
\cline { 2 - 7 } & Urea & ZA & SP 36 & NPK & Organik \\
\hline 1. Distributor PD Harapan Pajar & 0.83 & 2.14 & 2.40 & 2.60 & 6.01 \\
2. Pengecer Resmi & & & & & \\
a. Kios Abadi & 2.83 & 2.42 & 2.84 & 2.84 & 5.67 \\
b. Kios Harapan pajar & 2.83 & 1.59 & 1.85 & 2.38 & 3.01 \\
3.Kios Binaan & & & & & \\
c. Hadiri & 1.5 & 1.11 & 1.3 & 1.5 & 1.54 \\
d. Hamdan & 1.4 & 0.71 & 0.84 & 1.4 & 4.27 \\
e. Rusdi & 1.5 & 0.91 & 1.06 & 1.5 & 3 \\
f. Lomeu & 1.5 & 0.74 & 1.06 & 1.7 & 3 \\
g. Nardi & 1.5 & 0.91 & 1.06 & 1.5 & 3 \\
h. Suwardi & 1.5 & 0.91 & 1.06 & 1.5 & 3 \\
g. M. A. Halim & 1.7 & 0.91 & 1.06 & 1.5 & 3 \\
\hline
\end{tabular}

Sumber : Analisi Data Primer,2012 
Tabel di atas menunjukan bahwa pada lembaga pemasaran distributor dan lembaga pemasaran pengecer resmi tidak efisien karna jika di lihat berdasarkan kriteria keputusan apabila nilai efisiensi $<5 \%$ di katakan efisien dan nilai efisiensiny $>5 \%$ di katakan tidak efisien(Haripudin,Aisyah,Budiman:2011). Dimana pada lembaga distributor nilai efisiensi pemasaran pupuk organik adalah $6.01 \%$ maka bisa di katakan pemasarannya tidak efisien dan begitupula pada lembaga pemasaran pengecer resmi di mana untuk pupuk organik itu sendiri sebesar $5.67 \%$ maka juga di katakan tidak efisien. Hal ini dapat terjadi di karnakan nilai margin pemasaran yang di keluarkan oleh lembaga distributor dan pengecer resmi lebih besar jika di bandingkan biaya pemasaran yang di keluarkan oleh kios binaan. 


\section{KESIMPULAN DAN SARAN}

1. Berdasarkan analisis yang di lakukan bahwa saluran distribusi pupuk bersubsidi yang ada di daerah penelitian tidak berdasarkan SK Menperindak No. 17/M- DAG/PER/6/2011 yang di mulai dari:

Produsen $\longrightarrow$ Distributor $\longrightarrow$ Pengecer $\longrightarrow$ Resmi $\longrightarrow$ Petani.

Saluran distribusi pupuk bersubsidi yang ada di daerah penelitian:

Produsen $\longrightarrow$ Distributor $\longrightarrow$ Pengecer Resmi $\longrightarrow$ Pengecer Binaan $\longrightarrow$ Petani

Hal ini terjadi karena kurangnya pengecer resmi yang ada di daerah penelitian sehingga di bentuknya pengecer binaan guna memperlancar pendistribusian pupuk bersubsidi serta di dukung dengan lemahnya pengawasan yang dilakukan oleh Komisi Pengawasan Pupuk dan Pestisida ( KP3) di tingkat Kabupaten/Kota yang telah di tetapkan oleh Bupati/Walikota sehingga pengecer binaan dengan mudahnya memainkan harga kepada petani akibatnya petani yang di rugikan.

2. Lembaga distributor merupakan saluran pemasaran yang tidak efisien karna memiliki margin tataniaga yang tinggi di bandingkan lembaga tataniaga pengecer resmi dan pengecer binaan, sedangkan margin pemasaran terkecil di keluarkan oleh lembaga pengecer binaan sedangkan nilai share margin terbesar terdapat pada pengecer binaan, kemudian pengecer kios resmi dan yang paling rendah adalah distributor. Hal ini terjadi karena saluran pemasaran yang di lakukan distributor lebih panjang serta wilayah kerjanya luas di bandingkan lembaga pengecer resmi dan kios binaan sehingga biaya transportasi yang dikeluarkan menjadi lebih besar. Selain itu lembaga pemasaran distributor dan pengecer resmi merupakan saluran pemasaran yang tidak efisien jika di bandingkan lembaga pemasaran pengecer binaan. Hal ini dapat terjadi di karnakan nilai margin pemasaran yang di keluarkan oleh lembaga distributor dan pengecer resmi lebih besar jika di bandingkan biaya pemasaran yang di keluarkan oleh kios binaan.

Berdasarkan hasil penelitian yang telah di lakukan maka saran yang dapat di berikan dalam pendistribusian pupuk bersubsidi adalah sebagai berikut:

1. Seharusnya saluran distribusi pupukbersubsidi melalui satu saluran yang telah di tetapkan dalam SK Menperindak No.17/M- DAG/PER/6/2011 tanpa melalui pengecer binaan serta jumlah pengecer resmi yang ada di daerah penelitian di perbanyak jumlahnya agar tidak terbentuknya pengecer binaan yang pada akhirnya berdampak buruk kepada petani khususnya mengenai harga pupuk bersubsidi yang di terima oleh petani itu sendiri.

2. Perlu adanya lembaga koperasi yang menaungi para petani untuk menekan dan memperkecil selisih margin pemasaran pupuk bersubsidi agar para petani mendapatkan harga pupuk bersubsidi sesuai berdasarkan Harga Eceran pemerintah. Serta perlu adanya tenaga penyuluh tentang pupuk bersubsidi kepada petani khususnya mengenai Harga 


\section{DAFTAR PUSTAKA}

Agromedia,Redaksi,2007. Petunjuk Pemupukan. PT Agromedia Pustaka, Jakarta.

Anonimous, 2010. Tata Cara Penyusunan RDK ( rencana definitif kelompok). http:// www.scribd.com. Di akses pada tanggal 21 juni 2012

Anonimous, 2011. Efektivitas Pengadaan dan Penyaluran Pupuk Bersubsidi Terhadap Pemenuhan Kebutuhan Pupuk Petani Padi di Kecamatan Kumpeh Kabupaten Muaro Jambi.Jurnal Litbang Pertanian Vol. 29 (2) 2011, Hal 1-18.

Anonimous, 2011. Mekanisme Penyaluran Pupuk Bersubsidi dengan Sistem RDKK. http : // saluran distribusi pupuk bersubsidi blogspot. Com.Di akses pada tanggal 20 oktober 2012.

Anonimous, 2011. Faktor-Faktor yang Mempengaruhi Perilaku Petani di dalam Melakukan Kegiatan Usaha tani.http://elib.unicom.ac.id. di akses pada tanggal 1 september 2012

Anonimous, 2011. Laporan Praktikum Tataniaga http://kuliah - suim.blogspot.com di akses pada tanggal 18 april 2012.

Bisuk,Putra,2009.AnalisisTataniaga dan Elastisitas Tranmisi Harga CPO Internasional terhadap Harga TBS ( tandan buah segar ) Kelapa sawit di Desa Menanti Kecamatan Sosa Kabupaten Padang Lawas, skripsi mahasiswa Fakultas Pertanian Universitas Sumatera Utara Medan ( tidak di publikasikan ).

Downey, W. David dan Steven Erikson,1992.ManajemenAgribisnis, di terjemahkan oleh Rochdiat Ganda S, dan Alfonso Sirait. Erlangga: Jakarta.

Gitosudarmo,Indriyo,2000.Manajemen Pemasaran. BPFE : Yogyakarta.

Harifudin, Aisyah dan Budiman. Analisis Margin dan Efisiensi Pemasaran Rumput Laut di Desa Mandalle di Kecamatan Mandalle. Jurnal AGRIBISNIS Vol. X (3) September 2011, Hal 1-11.

Kotler dan Amstrong, 2001. Prinsip Prinsip Pemasaran. Erlangga:Jakarta.

Limbong, Wilson, H,Pangabean,Sitorus,1988. Pengantar Tataniaga Pertanian. Institut Pertanian Bogor: Bogor.

Lingga,Pinus,2007.Petunjuk Penggunaan Pupuk. Penebar Swadaya: Jakarta.

Mubyarto,1991.Pengantar Ekonomi Pertanian. LP3ES: Jakarta.

Sirait,Melda,2008.Analisis Pemasaran Pupuk Bersubsidi ( UREA, ZA, SP- 36, NPK,) di Kabupaten Simalungun, skripsi Mahasiswa Fakultas Pertanian Universitas Sumatra Utara: Medan ( tidak di publikasikan )

Soekartawi, 2002. Prinsip Dasar Manajemen Pemasaran Hasil-Hasil Pertanian. PT Raja Grafindo Persada : Jakarta.

Sutejo, Mulyani, 2002. Pupuk dan Cara Pemupukan. Rineka Cipta: Jakarta.

Sugiyono, 2007.Statistika untuk Penelitian.Alfabeta:Bandung

Sugiyono, 2010. Statistik untuk Penelitian.Alfabeta:Bandung.

Umar,Husein,2005.Riset Pemasaran dan Perilaku Konsumen. PT Gramedia Pustaka Utama: Jakarta. 